\title{
Neurocardiology: close interaction between heart and brain
}

\author{
E. E. van der Wall • W. H. van Gilst
}

Published online: 13 December 2012

(C) Springer Media / Bohn Stafleu van Loghum 2012

The interaction between heart and brain becomes increasingly important as the underlying mutual mechanisms become better understood. The speciality that deals with the brain-heart connection has become known as neurocardiology [1]. Neurocardiology refers to (patho)physiological interplays of the nervous and cardiovascular systems [2]. Baroreflex sensitivity and heart rate variability are important parameters in understanding the influence of the autonomic nervous system on both heart and brain activity [3, 4]. Over the past years, there is increasing evidence about the brainheart interaction with major potential implications for treatment of cardiovascular diseases. For instance, cerebrovascular accidents (CVAs) and transient ischaemic attacks (TIAs) are frequently caused by cardiac arrhythmias and/or congestive heart failure $[5,6]$. In particular atrial fibrillation may result in cognitive disorders preceding the occurrence of TIAs or CVAs [7-10]. Even in the absence of manifest stroke, atrial fibrillation is a risk factor for cognitive impairment and hippocampal atrophy. Therefore, cognition and measures of structural brain integrity should be considered in the evaluation of novel treatments for atrial fibrillation.

On the other hand, cerebrovascular dysfunction may lead to electrocardiographic disorders and cardiac rhythm disturbances. Subarachnoid bleeding may lead to dramatic electrocardiographic changes and even ventricular fibrillation, possibly due to QT-interval prolongation [11, 12]. Panic disorders and emotional distress such as the Takotsubo syndrome may give rise to (supra)ventricular tachycardias with ensuing transient left ventricular dysfunction [13-16]. Coronary artery bypass surgery (CABG) has major effects

E. E. van der Wall $(\bowtie) \cdot$ W. H. van Gilst

Interuniversity Cardiology Institute of the Netherlands (ICIN) -

Netherlands Heart Institute (NHI), Catharijnesingel 52,

3511 GC Utrecht, the Netherlands

e-mail: e.e.van_der_wall@lumc.nl

E. E. van der Wall

e-mail: ernst.van.der.wall@icin.knaw.nl on neurocognitive functioning [17]. However, the literature still remains undecided on the role of intra-operative emboli and cognitive decline after surgery [18]. More attention should be focussed on the composition, size and location instead of the absolute number of intra-operative emboli. Growing awareness of neuroncognitive decline in chronic vascular and congenital heart disease patients must challenge both clinicians and investigators [19]. Exercise stimuli may prevent or slow down the cognitive decline in elderly patients with heart failure. In particular, the therapeutic implications in the direct interrelation between the nervous system, the brain and the heart will increasingly become a dominant focus of forthcoming studies [20].

The future of therapeutic approaches in neurocardiology lies both in novel treatment as in applying scientific integrative medical ideas that take into account concurrent chronic degenerative and vascular disorders and interactions of multiple drug and non-drug treatments. In this respect, vagal stimulation, exercise training, electrical neurostimulation, music therapy, and -recently- renal denervation have become interesting options in the treatment of angina pectoris, heart failure, and hypertension [21-26]. Various patient groups (psychological distress, atrial fibrillation, heart failure, post-CABG) may benefit when the appropriate mechanisms of the interrelation between the nervous system, brain and heart become elucidated [27]. When these relationships are better understood, more appropriate therapeutic measures can be taken to benefit patients with cardiovascular and cerebrovascular diseases [28] .

In the beginning of 2011, the ICIN-Netherlands Heart Institute requested the Royal Academy of Sciences (KNAW) to set up an Academy Colloquium. Academy colloquia are initiatives of the KNAW consisting of symposia dedicated to an interesting scientific topic for a limited audience of 50 national and international individuals ( 15 speakers, 35 attendees). Fortunately, our request was granted to organise an academy colloquium entitled 'Neurocardiology: direct interaction between brain, heart, and nervous system'. The meeting was held on Thursday 31 May and Friday 1 June 2012, and 
turned out to be very successful in terms of excellent speakers and a very lively and experienced audience.

This special February 2013 issue is exclusively dedicated to the topic of our academy colloquium. To that purpose, most presenters have delivered nice and readable articles based on the presentations they gave during the colloquium. We gratefully thank all authors for their efforts and we hope that the readers of NHJ will enjoy reading the state-of-theart achievements in neurocardiology [29].

\section{References}

1. van der Wall EE. The brain-heart connection; a round trip. Neth Heart J. 2011;19:269-70.

2. Ritz K, van Buchem MA, Daemen MJ. The heart-brain connection: mechanistic insights and models. Neth Heart J. 2012 Nov 23. [Epub ahead of print] doi:10.1007/s12471-012-0348-9.

3. Swenne CA. Baroreflex sensitivity: mechanisms and measurement. Neth Heart J. 2012 Nov 23. [Epub ahead of print] doi:10.1007/s12471-012-0346-y.

4. La Rovere MT, Pinna GD, Maestri R, et al. Clinical value of baroreflex sensitivity. Neth Heart J. 2012 Nov 27. [Epub ahead of print] doi:10.1007/s12471-012-0349-8.

5. van der Wall EE. New insights in prevention, diagnosis and treatment of stroke: its relation with atrial fibrillation. Neth Heart J. 2012;20:141-2.

6. Verheugt FW. Antithrombotic therapy in heart failure. Neth Heart J. 2012;20:176-8.

7. Breet NJ, van Donkersgoed HE, van Werkum JW, et al. Is platelet inhibition due to thienopyridines increased in elderly patients, in patients with previous stroke and patients with low body weight as a possible explanation of an increased bleeding risk? Neth Heart J. 2011;19:279-84.

8. Swaans MJ, Post MC, Rensing BJ, et al. Percutaneous left atrial appendage closure for stroke prevention in atrial fibrillation. Neth Heart J. 2012;20:161-6.

9. Smit MD, Van Gelder IC. Risk-benefit ratio assessment for stroke prevention in intermediate risk atrial fibrillation patients: will TEE-based aspirin treatment fill the gap? Neth Heart J. 2011;19:212-3.

10. Dinh T, Baur LH, Pisters R, et al. TIARA pilot study group. Feasibility of TEE-guided stroke risk assessment in atrial fibrillationbackground, aims, design and baseline data of the TIARA pilot study. Neth Heart J. 2011;19:214-22.

11. Chatterjee $\mathrm{S}$. ECG changes in subarachnoid haemorrhage: a synopsis. Neth Heart J. 2011;19:31-4.
12. Kukla P, Jastrzebski M, Praefort W. J-wave-associated ventricular fibrillation in a patient with a subarachnoid haemorrhage. Europace. 2012;14:1063-4.

13. Frommeyer G, Eckardt L, Breithardt G. Panic attacks and supraventricular tachycardias: the chicken or the egg? Neth Heart J. 2012 Nov 23. [Epub ahead of print] doi:10.1007/s12471-012-0350-2.

14. Taggart $P$. Brain-heart interactions and cardiac ventricular arrhythmias. Neth Heart J. doi:10.1007/s12471-012-0365-8.

15. Postema PG, Wiersma JJ, van der Bilt IA, et al. Takotsubo cardiomyopathy shortly following pacemaker implantation-case report and review of the literature. Neth Heart J. 2012 Oct 11. [Epub ahead of print] doi:10.1007/s12471-012-0320-8.

16. Van der Wall EE. A broken heart: repair needed? Neth Heart J. 2012;20:1-2.

17. Bruggemans EF. Cognitive dysfunction after cardiac surgery: Pathophysiological mechanisms and preventive strategies. Neth Heart J. 2012 Nov 27. [Epub ahead of print] doi:10.1007/s12471-012-0347-x.

18. van der Wall EE. Left ventricular function plays a role in cognitive ageing. Neth Heart J. 2011;19:447-8.

19. Vis JC, De Bruin-Bon HA, Bouma BJ, et al. Adults with Down syndrome have reduced cardiac response after light exercise testing. Neth Heart J. 2012;20:264-9.

20. van der Horst IC, de Boer RA, Hillege HL, et al. Neurohormonal profile of patients with heart failure and diabetes. Neth Heart J. 2010;18:190-6.

21. Schwartz PJ. Vagal stimulation for heart diseases: from animals to men. An example of translational cardiology. Neth Heart J. doi:10.1007/s12471-012-0368-5.

22. Piepoli MF. Exercise training in chronic heart failure: mechanisms and therapies. Neth Heart J. doi:10.1007/s12471-012-0367-6.

23. De Decker K, Beese U, Staal MJ, et al. Electrical neuromodulation for patients with cardiac diseases. Neth Heart J. 2012 Nov 30. [Epub ahead of print] doi:10.1007/s12471-012-0356-9.

24. Sleight $P$. Cardiovascular effects of music by entraining cardiovascular autonomic rhythms music therapy update: tailored to each person, or does one size fit all? Neth Heart J. doi:10.1007/s12471-012-0359-6.

25. Voskuil M, Verloop WL, Blankestijn PJ, et al. Percutaneous renal denervation for the treatment of resistant essential hypertension; the first Dutch experience. Neth Heart J. 2011;19:319-23.

26. Verloop WL, Voskuil M, Doevendans PA. Renal denervation: a new treatment option in resistant arterial hypertension. Neth Heart J. 2012 Nov 30. [Epub ahead of print] doi:10.1007/s12471-012-0357-8.

27. de Morree HM, Szabó BM, Rutten GJ, et al. Central nervous system involvement in the autonomic responses to psychological distress. Neth Heart J. 2012 Nov 27. [Epub ahead of print] doi:10.1007/ s12471-012-0351-1.

28. Kemps HM, van Engen-Verheul MM, Kraaijenhagen RA, et al. Improving guideline adherence for cardiac rehabilitation in the Netherlands. Neth Heart J. 2011;19:285-9.

29. van der Wall EE. Amor and Psyche; a growing relationship? Neth Heart J. 2012;20:189-90. 